\title{
Effects of L-arginine on Some Cytogenetical and Physiological Parameters of Allium cepa L. Seeds exposed to Salinity
}

\author{
Dilek Çavuşoğlu
}

Department of Plant and Animal Production, Isparta University of Applied Sciences, Isparta, Turkey.

\begin{abstract}
In this study, L-arginine (Arg) effects on the seedling growth (fresh weight, radicle length and radicle number), seed germination, mitotic activity, chromosomal aberrations and micronucleus frequency in Allium cepa L. germinated in both salt stress and normal conditions were investigated. In only Arg medium, the radicle number of the seeds was partially reduced compared to the control seeds germinated in the distilled water medium, the fresh weight, radicle length and germination percentage indicated statistically the same values as the control. Besides, the mitotic index in the root tip meristems of A. cepa seeds germinated in the Arg medium alone showed a decrease compared to the control seeds germinated in the distilled water medium, whereas the chromosomal aberrations exhibited a significant increase compared to the control. Moreover, the micronucleus formation increased compared to the control. On the other hand, salt stress significantly inhibited the seedling growth and seed germination of A. cepa. In addition, it significantly reduced the mitotic index in the root tip meristems of the seeds and increased the number of chromosomal abnormalities and micronucleus frequency, which is the simplest indicator and the most effective of cytological damage. Nonetheless, the inhibitive effect of salt on the micronucleus formation, mitotic activity, seedling growth, seed germination and chromosomal aberrations significantly decreased with the application of L-arginine.
\end{abstract}

Keywords-Allium cepa L., arginine, salt stress, seed germination, mitotic index.

\section{INTRODUCTION}

Salinity or salt stress is an important abiotic factor that limits crop production. Soils with electric conductivity more than $40 \mathrm{mM} \mathrm{NaCl}$ (about $4 \mathrm{ds} / \mathrm{m}$ ) are considered to be salty. Approximately $7 \%$ of the earth's land [1] and 20 $\%$ of the irrigated land [2] are affected by salinity. More land is irrigated every year to increase crop production. Expansion of irrigated land, coupled with high salt content in irrigation water and poor drainage has increased salinity stress. Blumwald and Grover [3] predict that approximately $50 \%$ of arable land will be affected by salt stress in 2050. Improvement of drainage to improve crop production in saline soils, irrigation management, use and development of salt tolerant varieties are suitable solutions. Salt tolerance is that plants complete their life cycles and grow with good yield potentials in salt conditions. There are two salt tolerance mechanisms; osmotic effect that minimizing salt ingress from root to leaf and ionic effect which minimizes intracellular toxicity due to higher salt concentration [4].

Arginine (Arg), one of the twenty standard amino acids necessary for the formation of proteins and peptides, is also used as a nitrogen storage compound in seeds. In addition, Arg is the precursor of polyamines and nitric oxide, which play an important role in response to various environmental stresses and in many developmental processes. Arg is ideal for storing nitrogen due to its very high $\mathrm{N}: 4$ / $\mathrm{C}: 6$ ratio, which is a basic amino acid with $\mathrm{H}_{2} \mathrm{NC}(=\mathrm{NH}) \mathrm{NH}\left(\mathrm{CH}_{2}\right)_{3} \mathrm{CH}\left(\mathrm{NH}_{2}\right) \mathrm{COOH}$ linear formula. Indeed, Arg can be represented as a free amino acid in seeds such as soybean, pumkin, broad bean, many other dicotyledonous plants, peach tree or as an important part of the nitrogen store in, other parts of plants or bulbs. And this is an important amino acid in the free amino acid ponds of seedlings of early growth of both seedling growth and megagametophine. Therefore, its biosynthesis may be of additional importance during seed development. Ornithine, is a precursor of Arg and Arg is required for polyamine production. These small positively charged organic molecules play an important role in senescence, root growth, division, response to plant stress, cell growth, ripening, fruit development and other processes. Arg which is the source of nitric oxide plays an important role in root growth, defense, germination, responses, flowering and hormonal marking in plants. Arg is a dietary precursor for nitric oxide formation and nitric oxide is a potent mediator of vascular tone, hence affects the cardiovascular system. The nitric oxide formed from dietary Arg has been linked to muscle repair and 
optimal immune function [5]. Feirer [6] stated that the level of Arg increased twenty-fold during the embryo development in the seed. In addition, Arg which is a precursor of polyamines having a regulatory role in embryogenesis. Moreover, it has an important position in a transport compound and the urea cycle too [7].

Since the early 1920s, Allium cepa was used to assess the chromosome abnormalities. The method is a sensitive and easy tool to measure total toxicity caused by chemical treatments expressed by growth inhibition of onion bulb roots. Allium test was used as a standard test for cytogenotoxicity monitoring [8]. The test has some advantages, such as being very inexpensive, easy to apply, simple and also as reliable as the method in which abnormalities are recorded in all types of mitotic cells. It combines two test targets: using for toxicity\&genotoxicity monitoring, it is also an important fact that it shows a good correlation with mammalian test systems [9].

Although there are few published studies on the role of Arg on the seedling growth and seed germination under both saline and normal conditions, unfortunately, there are no studies on the effects of this amino acid on the micronucleus frequency, mitotic activity and chromosomal aberrations in saline and normal conditions. For these reasons, this work was designed to investigate the effects of Arg in reducing of the harmful effects of salt stress on the mitotic activity, seed germination, chromosomal aberrations, micronucleus frequency and seedling growth of Allium cepa $\mathrm{L}$.

\section{MATERIALS AND METHODS}

\subsection{Seed, arginine and salt concentrations}

In the present work, Allium cepa $\mathrm{L}$. seeds and $0.175 \mathrm{M}$ $\mathrm{NaCl}$ (salt) concentration were used. The concentration of $\mathrm{L}$-arginine used in the experiments was $10 \mathrm{mg} / \mathrm{L}$. Arg was obtained from Merck. In a preliminary investigation of this study, Arg and salt concentrations were determined conducted.

\subsection{Seed germination}

Seed germination experiments were performed in a (fixed temperature) incubator set to $20^{\circ} \mathrm{C}$ in the dark. Approximately equal-sized and healthy onion seeds have selected. Allium cepa L. (Amaryllidaceae) seeds have sterilized with the aid of sodium hypochloride solution $(2.5 \%)$ for ten minute and washed with ultra-pure water for 24 hour. Twenty seeds selected from each application group were placed in plastic containers. The bulbs have split in four groups:

$>$ Group I (control) during 7 sequential days have treated by distilled water.
$>$ Group II during 7 sequential days have treated by $0.175 \mathrm{M} \mathrm{NaCl}$ alone.

$>$ Group III during 7 sequential days have treated by a $10 \mathrm{mg} / \mathrm{L}$ dose of Arg.

$>$ Group IV during 7 sequential days have treated by a $10 \mathrm{mg} / \mathrm{L}$ dose of $\mathrm{Arg}+0.175 \mathrm{M} \mathrm{NaCl}$.

It is assumed that the seeds in plastic containers placed in the incubator for germination should have a length of $10 \mathrm{~mm}$. After 7 days, the final germination percentage was taken, the number of radicle were recorded, the radicle lengths of onions were measured in $\mathrm{mm}$, the fresh weights were also determined in $\mathrm{g} / \mathrm{seed}$. All experiments were repeated 3 times.

\subsection{Cytological and statistical analysis}

After a few days for cytogenetic analysis, 1-1.5 cm segment of germinated A. cepa's root tips were excised. Initially, these have pretreated using saturated paradichlorobenzene for four hours, afterwards were fixed in a solution (3:ethanol / 1: acetic acid) for 24 hours at room temperature and stock up in $70 \%$ ethanol at $4^{\circ} \mathrm{C}$ until making the microscopic slides. A. cepa rootlets were hydrolysed for 15 minutes in $1 \mathrm{~N} \mathrm{HCl}$ at $60^{\circ} \mathrm{C}$, dyed with Feulgen for 1-1.5 hours and lysed with a drop of $45 \%$ $\mathrm{CH}_{3} \mathrm{COOH}$. Squashes have prepared as suggested by Sharma and Gupta [10]. At the end of 24 hours, microscopic preparations were made permanent by means of balsame. With a digital camera (Olympus C-5060) mounted on the Olympus CX41 microscope has photographed mitotic phases, micronuclei and mitotic aberrations (500X).

The cell division densities of these preparations were analyzed by calculating the mitotic index (\%) (MI) assessed by analyzing at least 30000 cells per sample (about 10000 per preparation). Chromosomal abnormalities were calculated as the percentage of 2000 dividing cells counted for each concentration. The latter was determined as a percentage between the number of dividing cells (N') and the total number of cells analyzed $(\mathrm{N})$ according to formula: $\mathrm{MI}(\%)=\left(\mathrm{N}^{\prime} / \mathrm{N}\right)$ x 100 [11]. The statistical analysis was carried out using SPSS program according to DMRT. Statistically, all values mentioned in this study are highly significant $(\mathrm{P}<0.05)$.

\subsection{Micronucleus (MN) assay}

For micronucleus analyses, 1000 cells per slide were scored. MN was examined with the help of a binocular light microscope. For the scoring of micronucleated cells, Fenech et al. [12] used the protocol they followed. These: (i) the diameter of the micronucleus should be a tenth of 
the main nucleus, (ii) Micronucleus should be separated from or marginally overlapped from the main nucleus, provided that the nucleus boundary is clearly defined, (iii) the micronucleus staining should be similar to that of the main nucleus.

\section{RESULTS}

3.1. Effects of arginine on the seedling growth and seed germination

The results from Table 1 clearly demonstrate that while the radicle length, fresh weight and germination percentage of group III germinated in alone Arg medium showed statistically the same values as group I (control) germinated in distilled water medium, their radicle number partly decreased according to the control seeds.

$\mathrm{NaCl}$ exhibited an inhibitory effects on all growth parameters examined. For instance, the control (group I) seeds germinated in distilled water medium after 7 days showed $100 \%$ germination, whereas this value was $23 \%$ in group II seeds germinated at $0.175 \mathrm{M}$ salinity. That is to say, $\mathrm{NaCl}$ prevented $77 \%$ germination of Allium cepa seeds. The inhibitive effect of salt stress on the seed germination was markedly mitigated by Arg application. Group IV seeds treated with Arg in this salt level demonstrated $82 \%$ germination. In addition, Arg continued its success on the seedling growth parameters such as the fresh weight and radicle number. However, this amino acid has been ineffective in attenuating the negative effect of $\mathrm{NaCl}$ inhibition on the radicle length. The number of radicle and fresh weight of group II seedlings grown in $0.175 \mathrm{M}$ salinity were 12.7 and $7.0 \mathrm{~g}$, respectively while these values became 18.2 and $11.1 \mathrm{~g}$ in group IV seedlings treated with Arg (Table 1, Fig. 1).

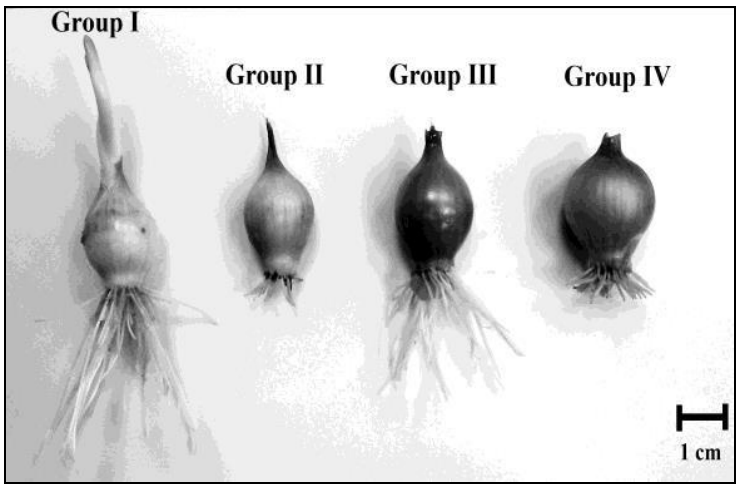

Fig. 1: Allium cepa root tip cells showing germination situations at the end of the seventh day. Control (Group I) seeds were treated with distilled water; Group II seeds were treated with $0.175 \mathrm{M} \mathrm{NaCl}$ alone; Group III seeds were treated with a $10 \mathrm{mg} \mathrm{L}^{-1}$ dose of L-arginine; Group

IV seeds were treated with a $10 \mathrm{mg} \mathrm{L}^{-1}$ dose of $L$ arginine $+0.175 \mathrm{M} \mathrm{NaCl}$. Scale bar $=1 \mathrm{~cm}$

Table 1: Effects of L-arginine on some growth parameters of Allium cepa L.

\begin{tabular}{ccccc}
\hline & \multicolumn{2}{c}{ Growth parameters } \\
\cline { 2 - 5 } Groups & $\begin{array}{c}\text { Germination } \\
\text { percentage } \\
(\%)\end{array}$ & $\begin{array}{c}\text { Radicle } \\
\text { length } \\
(\mathbf{m m})\end{array}$ & $\begin{array}{c}\text { Radicle } \\
\text { number }\end{array}$ & $\begin{array}{c}\text { Fresh } \\
\text { Weight } \\
(\mathbf{g} / \text { seedling })\end{array}$ \\
\hline Group I & ${ }^{*} 100 \pm 0.0^{\mathrm{c}}$ & $63.5 \pm 0.5^{\mathrm{b}}$ & $63.2 \pm 0.6^{\mathrm{d}}$ & $14.2 \pm 0.8^{\mathrm{c}}$ \\
\hline Group II & $23 \pm 2.8^{\mathrm{a}}$ & $10.3 \pm 0.3^{\mathrm{a}}$ & $12.7 \pm 0.5^{\mathrm{a}}$ & $7.0 \pm 0.5^{\mathrm{a}}$ \\
\hline Group III & $100 \pm 0.0^{\mathrm{c}}$ & $63.4 \pm 1.0^{\mathrm{b}}$ & $56.0 \pm 0.5^{\mathrm{c}}$ & $14.3 \pm 0.3^{\mathrm{c}}$ \\
\hline Group IV & $82 \pm 2.8^{\mathrm{b}}$ & $11.1 \pm 0.9^{\mathrm{a}}$ & $18.2 \pm 0.5^{\mathrm{b}}$ & $11.1 \pm 0.6^{\mathrm{b}}$ \\
\hline
\end{tabular}

*The difference between the values in each column and the same letters isn't significant at the 0.05 level $( \pm \mathrm{SD})$. Control (Group I) seeds were treated with distilled water; Group II seeds were treated with $0.175 \mathrm{M} \mathrm{NaCl}$ alone; Group III seeds were treated with a $10 \mathrm{mg} \mathrm{L}^{-1}$ dose of L-arginine; Group IV seeds were treated with a $10 \mathrm{mg} \mathrm{L}^{-1}$ dose of L-arginine+0.175 M NaCl.

3.2. Effects of arginine on the micronucleus formation, chromosomal aberrations and mitotic activity

The mitotic index of group III seeds germinated in only Arg medium reduced $20 \%$ compared to group I (control) seeds germinated in distilled water medium. In addition, Arg application increased the chromosomal aberrations and frequency of the micronucleus according to the control
(Table 2). Exposure to $0.175 \mathrm{M}$ salinity resulted in a significant inhibition in the mitotic index. In an other words, the mitotic index in the root tip meristems of group II seeds germinated in $0.175 \mathrm{M}$ salt media compared to the group I seeds (distilled water, control) decreased by $89 \%$ and increased significantly the chromosome aberrations (17\%) and the frequency of micronucleus (13\%). On the other hand, Arg treatment became successful in improving 
the adverse effects of salinity on the micronucleus formation, mitotic activity and chromosomal aberrations. These values became $9.6 \%(\mathrm{MN}), 9.1 \%(\mathrm{MI})$ and $13.6 \%$ (CAs) in group IV seeds treated with Arg (Table 2).

Figure 2 shows the abnormal mitotic phases observed in course of microscopic examination in meristem cells of A. cepa root tip. Double nuclear lesion and micronucleus were the most frequent abnormalities induced by Arg and its salt constituents. Some other aberrations were also observed in cells with the frequency of occurrence as: nucleus disintegration $>$ polar deviation in telophase $>$ anaphase with vagrant chromosome $>$ scattering at metaphase $>$ telophase with vagrant chromosomes $>$ condansed nuclei $>$ uncoiling chromosomes $>$ alignment anaphase $>$ laggards at anaphase $>$ notched nuclei $>$ ring chromosome $>$ nuclear bud $>$ giant cell $>$ prophase with chromosome loss $>$ anaphase with chromosome loss $>$ disturbed in telophase.

Table 2: Effect of L-arginine on some cytogenetic parameters of Allium cepa $L$.

\begin{tabular}{|c|c|c|c|}
\hline Groups & $\begin{array}{c}\text { Mitotic index } \\
(\%)\end{array}$ & $\begin{array}{l}\text { Micronucleus } \\
\text { frequency }(\%)\end{array}$ & $\begin{array}{c}\text { Chromosome } \\
\text { aberration (\%) }\end{array}$ \\
\hline Group I & $* 11.6 \pm 1.0^{\mathrm{c}}$ & $0.0 \pm 0.0^{\mathrm{a}}$ & $0.0 \pm 0.0^{\mathrm{a}}$ \\
\hline Group II & $1.2 \pm 0.2^{\mathrm{a}}$ & $13.0 \pm 1.0^{\mathrm{d}}$ & $17.0 \pm 0.4^{\mathrm{c}}$ \\
\hline Group III & $9.2 \pm 0.5^{b}$ & $1.3 \pm 0.5^{b}$ & $14.3 \pm 0.5^{b}$ \\
\hline Group IV & $9.1 \pm 0.3^{b}$ & $9.6 \pm 0.5^{\mathrm{c}}$ & $13.6 \pm 1.3^{\mathrm{b}}$ \\
\hline
\end{tabular}

*The difference between the values in each column and the same letters isn't significant at the 0.05 level ( \pm SD). Control (Group I) seeds were treated with distilled water; Group II seeds were treated with $0.175 \mathrm{M} \mathrm{NaCl}$ alone; Group III seeds were treated with a $10 \mathrm{mg} \mathrm{L}^{-1}$ dose of L-arginine; Group IV seeds were treated with a $10 \mathrm{mg} \mathrm{L}^{-1}$ dose of L-arginine+0.175 M $\mathrm{NaCl}$.

\section{DISCUSSIONS}

4.1. Cytogenetical and physiological effects of exogenous arginine under normal conditions

If stress conditions are not present in the environment, any plant growth regulator should be added as exogenous in the germination process. The addition of a plant growth regulator exogenously under stress-free conditions can have negative or positive effect on the seedling growth and seed germination [13, 14]. However, there are few studies on the effects of Arg on the seed germination and seedling growth under normal conditions. Therefore, in the laboratory study, the effects of Arg application on the mitotic activity, seed germination, micronucleus frequency, chromosomal aberrations and seedling growth under normal conditions requested to be tested. The seed germination depending on the used concentration, application method and plant species. laboratory study's results revealed that the germination percentage, fresh weight and radicle length of the seeds germinated in the only Arg medium statistically showed the same values as the control seeds germinated in distilled water medium, whereas their radicle number decreased slightly compared to the control (Table 1). ElBassiouny et al. [15] reported that $0.6,1.25,2.5$ and 5 $\mathrm{mM}$ Arg applications increased significantly the fresh weights of wheat seedlings grown in normal conditions. Samia and Rania [16] determinated that $2.5 \mathrm{mM}$ Arg resulted in obvious enhancement in the radicle length and fresh weights of lupine seedlings under normal conditions. These results are not consistent with the present research findings, so Arg may have different effects on the seedling growth and 


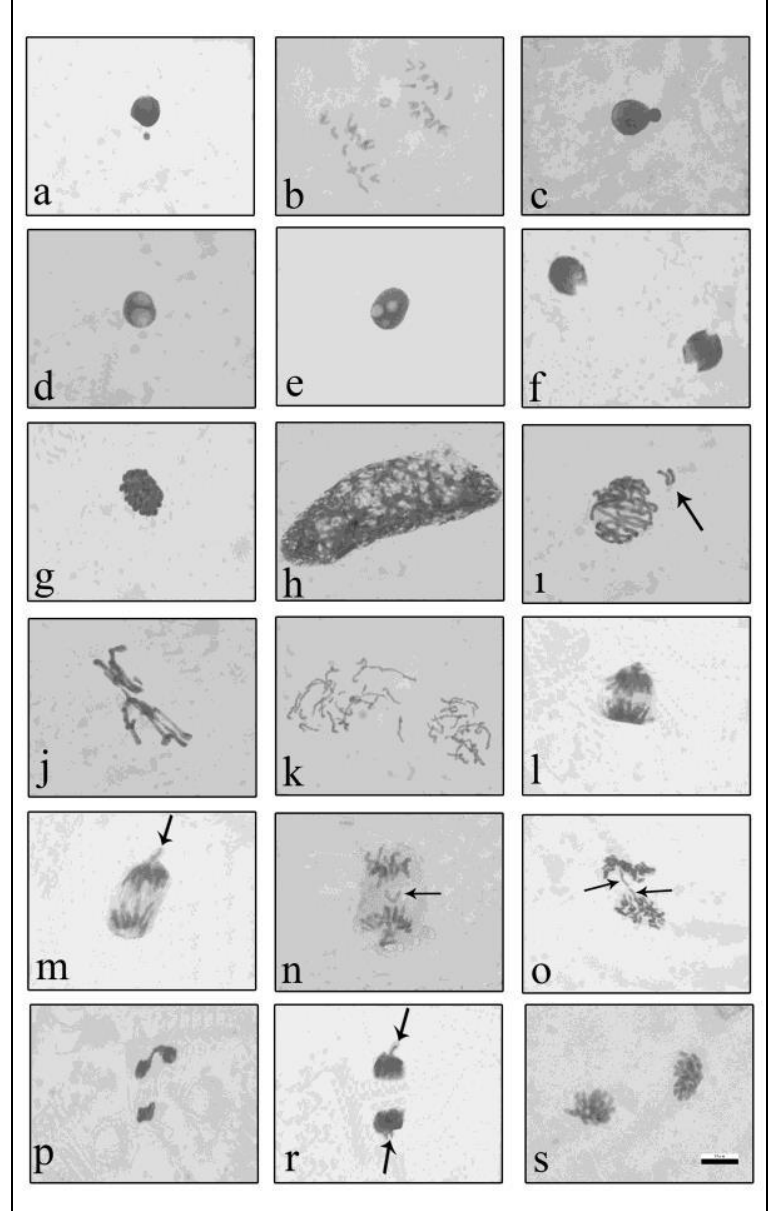

Fig. 2: Chromosomal aberrations; a-micronucleus; b-ring chromosome; $c$-nuclear bud; $d$-double nuclear lesion; $e$ nucleus disintegration; f-notched nuclei; g-condansed nucleus; h-giant cell; l-prophase with chromosome loss=arrow; j-uncoiling chromosomes; $k$-scattering at metaphase; l-alignment anaphase; m-anaphase with

vagrant chromosome= arrow; $n$-anaphase with chromosome loss=arrow; o-laggards at anaphase =arrows; $p$-disturbed in telophase; $r$-telophase with vagrant chromosomes=arrows; s-polar deviation in telophase. Scale bar $=10 \mu \mathrm{m}$

The effects on the chromosomal aberrations, mitotic activity and micronucleus frequency of Arg application under normal conditions are still unknown. The findings of this study showed that the MI in root meristems of A. cepa seeds subjected to Arg application under normal conditions decreased about $20 \%$ compared to the control seeds germinated in distilled water medium. Thus, administration of $10 \mathrm{mg} \mathrm{L}^{-1}$ Arg demonstrated an effect repressive on the mitotic activity by slowing cell division. This dose of Arg application increased markedly CAs and MN frequency according to the control. In this case, some abnormalities can be said to be caused by this stimulator (Table 2). In this study, micronucleus and double nuclear lesion were the most frequent abnormalities. Various abnormalities have been observed in all stages of mitotic division as a result of structural deviations in chromosomes. A part of the chromosomes can be connected to each other instead of separating to the poles forming fragments and bridges. Laggards observed occured during the chromosomal migration to the poles. Vagrant chromosome in anaphase may also be mainly the result of non-polar mitotic spindles.

4.2. Cytogenetical and physiological effects of exogenous arginine under saline conditions

Salt stress like many other abiotic stresses inhibits plant growth. Because the high salt concentration in the soil solution prevents from being absorbed the nutrient ions in a balanced manner by the plants. $\mathrm{NaCl}$ stress affects plant physiology in all plants and also affects cellular levels through osmotic and ionic adjustments resulting in a reduction in biomass production. The negative impact of salt stress is possible to see at all plant levels in almost all growth stages including, seedling, germination, maturity and herbal stages. Although salinity causes ionic and osmotic stress, it causes ionic imbalances that may induce potassium deficiency and may impair the selectivity of root membranes [17]. The results from Table 1 clearly demonstrated that as expected the seedling growth and germination of $A$. сера seeds were inhibited under saline conditions. In agriculture, soil salinity indicates the presence of high concentrations of soluble salts in the soil moisture of the root zone. Due to their high osmotic pressures, the concentrations of these soluble salts affect plant growth by limiting the water uptake of the roots [17]. Results of these statements are consistent with the results of the present study in terms of showing the decrease in the water content and fresh weight of the seedlings in salted conditions. The inhibitive effect of $\mathrm{NaCl}$ on the radicle number and radicle length may result from reducing protein synthesis, nucleic acid and cell division [18].

On the other hand, by application of the amino acid Arg, the inhibitory effect of saltinity stress on the seed germination, fresh weight and radicle number was significantly eliminated (Table 1). To date, there have been several studies investigating the effects of Arg on the seedling growth and seed germination in saline conditions. Abd El-Monem [19] found that the optimum concentration of Arg was $2.5 \mathrm{mM}$ in alleviating the harmful effects of salt stress in wheat. Zeid [20] observed that $4 \mathrm{mM}$ Arg pretreatment promoted the growth parameters and germination percentage of bean seedlings under salinity stress. Nasibi et al. [21] also showed that pre-treatment with three concentrations of $\operatorname{Arg}(0,5$ and $10 \mu \mathrm{M})$ could 
reduce the harmful effect of salinity on the fresh weight of canola seedlings. Nejadalimoradi et al. [22] observed that 1 and $5 \mathrm{mM}$ Arg pretreatment increased to the radicle length of sunflower plants under salinity stress. In addition, Samia and Rania [16] determinated that spraying $2.5 \mathrm{mM}$ Arg attenuated the retarder effects of salt stress in lupine plants. All of these results are consistent with the amino acid arginine's findings. As can be seen in Table 1, Arg can be understood from the decrease in the osmotic effects of the salt, which relieves the salt stress on the seedling growth and seed germination. For example, in $0.175 \mathrm{M} \mathrm{NaCl}$ medium, it is observed that the fresh weight of seedlings is significantly increased by Arg application compared to Group I indicates this probability. Additionally, Arg may have been successful in reducing the inhibitive effects of salinity stress on the seedling growth and seed germination by increasing antioxidant enzyme activities [21].

Mitotic index is a reliable parameter that reflects the frequency of cell division in the root growth area and is used to identify cytotoxicity [8]. Cytotoxicity levels can be determined by a decrease or an increase in the mitotic index [23]. The mitotic index can be used to determine root growth rate and as a reflection of cell proliferation. More interestingly, this study results showed that the salt caused a decrease in the mitotic activity and this decrease was achieved by decreasing the number of cells entering mitotic division. The decrease in the number of divided cells suggests that the salt may have mitodepressive effects on A. сера L. cell division. Mitodepression blocks nucleus proteins and DNA synthesis [24]. With this study, it should be noted that the salinity adversely affects chromosome behaviors and the mitotic activity of $A$. серa root meristem cells. The results of this study show that salinity decreased MI by $89 \%$ compared to the control group and showed an excessive increase in the number of chromosomal abnormalities and micronucleus. For example, while the MN and CAs in the root tip meristems in group I were $0.0 \%$ and $0.0 \%$, respectively these values became $13.0 \%$ and $17.0 \%$ in $0.175 \mathrm{M}$ salt. Furthermore, $\mathrm{Arg}+\mathrm{NaCl}$ became effective in alleviating the harmful effect of salt on the MI. In contrast, administration of simultaneously Arg+ $\mathrm{NaCl}$ showed a significant success compared to the Arg alone in alleviating the harmful effects of salinity on the frequency of MN and CAs. So, the frequency of CAs with the application of simultaneously $\mathrm{Arg}+\mathrm{NaCl}$ decreased by $20 \%$. This result shows Arg repair role against salt injuries during A. cepa's mitosis (Table 2).

Chromosomal abnormalities (CAs), which may occur as a result of both spontaneous and exposure to physical or chemical agents, are characterized by changes in the total chromosome number or chromosomal structure. Chemical and physical agents can induce CAs, which is carried out by different mechanisms including aneugenic and clastogenic actions. While aneugenic effect involves inactivation of a cell structure such as mitotic spindles leading to chromosomal losses, clatogenic effect is characterized by induction of chromosomal break during cell division. Nuclear abnormalities are derived from various types of CAs such as micronucleus, lobed nuclei, mini cells, nuclear buds and polynuclear cells. A number of chromosomal abnormalities are derived from nuclear abnormalities such as micronuclei, lobated nuclei, polinucleated cells, nuclear buds and mini cells. Micronucleus (Fig. 2a) may originate from all chromosomes (clastogenic agent) or from acentric fragments (aneugenic agent) not included in the main nucleus during the cell cycle [25]. Ring chromosomes (Fig. 2b) are the result of chromosome losses in the telomere domain [26]. Nuclear buds (Fig. 2c) associated with the formation of micronucleus are indicative of the initial process to discard nuclear material [23]. According to Akaneme and Iyioke [27], the presence of nuclear lesions (Fig. 2d) indicates cytological evidences for the inhibitory effect on DNA biosynthesis. Giant cells (Fig. $2 \mathrm{~h}$ ) occur due to incomplete cytoplasmic division but they grow up with nuclear division and DNA replication before they die [28]. The presence of vagrant chromosomes (Fig. $\mathrm{m}, \mathrm{r}$ ) means a deviation of mitotic spindle irregularity, an aberration which may result in delayed metaphase and /or prophase [29].

\section{CONCLUSION}

There are no literature data on the cytogenetic parameters examined in normal and saline conditions. Therefore, the results of this study have been particularly reported for the first time in normal and saline conditions. As a conclusion, this study showed that Arg can significantly increase activations such as the seed germination, seedling growth, mitotic index, $\mathrm{MN}$ and $\mathrm{CAs}$ under saline or normal conditions.

\section{REFERENCES}

[1] Aoki, A., Kanegami, A., Mihara, M., Kojima, T., Shiraiwa, M., Takahara, H. (2005). Molecular characterization of a novel soybean gene encoding a leucine-zipper-like protein induced to salt stress. Gene. 356, 135-145.

[2] Flowers, T.J., Yeo, A.R. (1995). Breeding for salinity resistance in crop plants. Where next?. Australian Journal of Plant Physiology. 22, 875-884.

[3] E. Blumwald and A. Grover, "Salt tolerance: Current and future uses of genetically modified crops" in Plant 
Biotechnology, G. Nigel and Halford, Eds. Cambridge: United Kingdom, 2006, pp. 206-224.

[4] Stoddard, F.L., Balko, C., Erskine, W., Khan, H.R., Link, W., Sarker, A. (2006). Screening techniques and sources of resistance to abiotic stresses in cool-season food legumes. Euphytica. 147, 167-186.

[5] Garcia, A. G. M. (2017). Hemp: a composition review plus. Senior project for Bachelor of Science Nutrition at California Polytechnic State University San Luis Obispo, C.A., pp. 1-83.

[6] R.P. Feirer, "The biochemistry of conifer embryo development: amino acids, polyamines and storage proteins" in Somatic embryogenesis in woody plants, S.M. Jain, P.K. Gupta, R.J. Newton, Eds. Dordrecht: Kluwer Academic Publishers, 1995, vol. 1, 317-336.

[7] Kärkönen, A. (2001). Plant tissue cultures as models for tree physiology: Somatic embryogenesis of Tilia cordata and lignin biosynthesis in Picea abies suspension cultures as care studies, Dissertation, Helsinki: Univ. of Helsinki.

[8] Fiskesjo, G. (1985). The Allium test as a standard in environmental monitoring. Hereditas. 102, 99-112.

[9] H. L. Yi and Z. Q. Meng, "Municipal landfill lechate induces cytogenetic damage in root tips of Hordeum vulgare" in Acta Phyto Ecotoxicology and Environmental Safety. N. Sang, G. Li, X. Xin, Eds. vol. 63, 2002, pp. 469473.

[10] Sharma, P.C., Gupta, P.K. (1982). Karyotypes in some pulse crops. Nucleus. 25, 181-185.

[11] Aslantürk, Ö.S., Çelik, T.A. (2005). Preventive effect of lycopene on chromosome aberrations in Allium cepa. Pakistan Journal of Biological Science. 8, 482-486.

[12] Fenech, M., Chang, W.P., Kirsch-Volders, M., Holland, N., Bonassi, S., Zeiger, E. (2003). HUMN (human micronucleus) project: detailed description of the scoring criteria for the cytokinesis-block micronucleus assay using isolated human lymphocyte cultures. Mutation Research. $534,65-75$.

[13] Çavuşoğlu, D. (2019). Physiological and cytogenetical effects of L-Tyrosine in Allium cepa $\mathrm{L}$. exposed to $\mathrm{NaCl}$ stress. Fresenius Environmental Bulletin. 28 (12A), 97539759.

[14] Çavuşoğlu, K., Doğu, F., Çavuşoğlu, D. (2019). Effects of Sodium Hypochlorite ( $\mathrm{NaClO}$ ) on some Physiological and Cytogenetical Parameters in Allium cepa L. Exposed to Salt Stress. Bangladesh Journal of Botany. 48(2), 223-229.

[15] El-Bassiouny, H.M.S., Mostafa, H.A., El-Khawas, S.A., Hassanein, R.A., Khalil, S.I., Abd El-Monem, A.A. (2008). Physiological responses of wheat plant to foliar treatments with arginine or putrescine. Australian Journal of Basic Applied Sciences. 2(4), 1390-1403.

[16] Samia, A.A., Rania, S.H. (2018). Alleviation of oxidative effects of salt stress in White lupine (Lupinus termis L.) plants by foliar treatment with L-Arginine. Journal of Animal and Plant Sciences. 28(1), 165-176.

[17] Nawaz, K., Hussain, K., Majeed, A., Khan, F., Afghan, S., and Ali, K. (2010). Fatality of salt stress to plants:
Morphological, physiological and biochemical aspects. African Journal Biotechnology. 9(34), 5475-5480.

[18] Mccue, K.F., Hanson, A.D. (1990). Drought and salt tolerance: towards understanding and application. Trends Biotechnology. 8, 358-362.

[19] Abd El-Monem, A.A. (2007). Polyamines as modulators of wheat growth, metabolism and reproductive development under high temperature stress, Dissertation, Cairo: Ain Shams Univ.

[20] Zeid, I. M. (2009). Trehalose as osmoprotectant for maize under salinity-induced stress. Research Journal of Agriculture and Biological Scences. 5, 613-622.

[21] Nasibi, F., Manouchehri, K.K.H., Barand, A. (2014). Effects of seed pre-treatment with L-arginine on improvement of seedling growth and alleviation of oxidative damage in canola plants subjected to salt stress. International Journal of Plant Production. 5(1), 12171224.

[22] Nejadalımoradı, H., Nasibi, F., Manoochehri, K., Kalantari, K., Zanganeh, R. (2014). Effect of seed priming with Larginine and sodium nitroprusside on some physiological parameters and antioxidant enzymes of sunflower plants exposed to salt stress. Agricultural Communications. 2(1), 23-30.

[23] Fernandes, T.C.C., Mazzeo, D.E.C., Marin-Morales, M.A. (2007). Mechanism of micronuclei formation in polyploidizated cells of Allium cepa exposed to trifluralin herbicide. Pesticide Biochemstry and Physiology. 88, 252259.

[24] Schulze, E., Kirschner, S. (1986). Microtubule dynamics in interphase cells. Journal of Cell Biology. 102, 1020-1031.

[25] Fenech, M. (2000). The in vitro micronucleus technique. Mutation Research. 455, 81-95.

[26] Khanna, N., Sharma, S. (2013). Allium cepa root chromosomal aberration assay. Indian Journal of Pharmaceutical and Biological Research. 1, 105-119.

[27] Akaneme, F.I., Amaefule, C.C. (2012). Evaluation of the cytotoxicity and genotoxicity of aqueous leaf extracts of Azardirachta indica A. Juss. using the Allium test. Journal of Medicinal Plants Research. 6, 3898-3907.

[28] Prajitha, V., Thoppil, J.E. (2014). Induction of giant cells by the synthetic food colorants viz. lemon yellow \& orange red. Cytotech. 68(3), 443-450.

[29] Tkalec, M., Malaric, K., Pavlica, M., Pevalek-Kozlina, B., Vidakovic-Cifrek, Z. (2009). Effects of radiofrequency electromagnetic fields on seed germination and root meristematic cells of Allium cepa L. Mutation ResearchFundamental and Molecular Mechanisms of Mutagenesis. $672,76-81$. 